\title{
KAJIAN JENIS MINERALOGI LEMPUNG DAN IMPLIKASINYA DENGAN GERAKAN TANAH
}

\section{STUDY OF CLAY MINERAL TYPE AND ITS IMPLICATION TOWARD LANDSLIDE}

\author{
Dyah Nursita Utami ${ }^{1}$ \\ ${ }^{1}$ Perekayasa Pertama pada Pusat Teknologi Reduksi Risiko Bencana (PTRRB) - BPPT. \\ Gedung 820 Lantai 1, Komplek Perkantoran PUSPIPTEK, Tangerang Selatan, Banten 15314. \\ e-mail: dyah.nursita@bppt.go.id
}

\begin{abstract}
Indonesia is a tropical region which is located in the geographical location of the equator, that causing some areas in Indonesia covered by soil types from intensive weathering of rocks. A combination with varied topography caused Indonesia had high vulnerability on landslide disaster. From the process of diagenesis and decomposition of rocks, soil that formed in Indonesia is very vulnerable toward landslide.. The process will also affect the abundance of clay minerals and their properties. Clay minerals that becomes a constituent the soil body greatly influences the nature of the soil is formed, both the nature of chemistry, biology, nature and physical properties of the soil. Clay minerals composing the expansive soil posses geotechnical and geochemical characteristics and able to influence material on the earth surface. This study aims to find out the type and nature of the mineralogy of clays, as well as the implications for landslide. Therefore, understanding the character type of mineralogy in clays is very important in landslide hazard mitigation in landslide-prone areas.
\end{abstract}

Keywords: soil type, expansive soil, clay mineral, landslide mitigation

\begin{abstract}
ABSTRAK
Indonesia merupakan daerah beriklim tropis yang terletak pada lokasi geografis khatulistiwa, menyebabkan sebagian wilayah di Indonesia ditutupi oleh jenis tanah dari pelapukan batuan yang berlangsung intensif. Perpaduan dengan topografi yang bervariasi menyebabkan Indonesia mempunyai kerentanan tinggi terhadap adanya bencana gerakan tanah. Dari proses diagenesis dan dekomposisi batuan, tanah yang terbentuk di Indonesia mempunyai sifat ekspansif yang sangat rentan menjadi pemicu gerakan tanah. Dari proses ini juga akan mempengaruhi kelimpahan mineral lempung beserta sifat-sifatnya. Mineral lempung yang menjadi penyusun sebuah tubuh tanah sangat mempengaruhi sifat tanah yang terbentuk, baik sifat kimia, sifat biologi, dan sifat fisik tanah. Mineral lempung yang menyusun dan terdapat pada tanah lunak atau tanah ekspansif mempunyai karakteristik pembawa sifat geoteknik dan geokimia yang dapat mempengaruhi apapun yang ada di atasnya. Kajian ini bertujuan mengetahui tipe dan sifat dari mineralogi lempung, serta implikasinya terhadap gerakan tanah. Oleh karena itu, pemahaman karakter tipe mineralogi lempung sangat penting dalam mitigasi bencana gerakan tanah di wilayah rawan gerakan tanah.
\end{abstract}

Kata kunci: jenis tanah, tanah ekspansif, mineral lempung, mitigasi gerakan tanah

\section{PENDAHULUAN}

\subsection{Latar Belakang}

Indonesia dengan curah hujan yang tinggi, dan memiliki topografi yang bervariasi. Adanya posisi yang seperti itu, maka secara geologis, geomorfologis dan klimatologis Indonesia selalu menghadapi bencana alam seperti, gerakan tanah (longsor), letusan gunung api, gempa bumi, banjir dan lain-lainnya. Setiap 
tahun beberapa wilayah di Indonesia mengalami bencana gerakan tanah. Gerakan tanah tersebut mengakibatkan kerugian materi dan juga hampir selalu menelan korban jiwa. Berdasarkan data sampai bulan mei tahun 2018 dari Badan Nasional Penanggulangan Bencana menunjukkan adanya 268 kejadian gerakan tanah dengan korban jiwa yang meninggal dan hilang 63 jiwa, luka-luka 76 jiwa, terdampak dan mengungsi sebanyak 35.601 jiwa.

Kejadian gerakan tanah umumnya berskala kecil, tidak sehebat gempa bumi, tsunami maupun gunung meletus, sehingga perhatian pada masalah ini umumnya tidak terlalu besar, ditambah lagi bahaya bencana gerakan tanah kurang diperhatikan dalam perencanaan pembangunan. Keadaan topografi pada relief bergunung-gunung disetiap wilayahnya, menjadikan Indonesia sangat berpotensi mengalami gerakan tanah.

Kondisi alamiah tersebut semakin diperparah dan diperberat karena kerusakan lingkungan berupa konversi lahan bervegetasi menjadi lahan budidaya atau bahkan menjadi lahan tidak bervegetasi, sehingga hal ini menyebabkan peningkatan kerawanan dan frekuensi kejadian bencana alam, salah satunya gerakan tanah.

Berbicara tentang bencana gerakan tanah, tak lepas dari mengkaji tentang faktor-faktor penyebab terjadinya gerakan tanah. Faktor penyebab gerakan tanah merupakan sebuah fungsi yang berkaitan satu sama lain. Salah satunya adalah geomofologi lahan yang terbentuk dari proses yang berbeda-beda di setiap wilayah. Hal tersebut yang mengakibatkan adanya perbedaan jenis tanah pada setiap wilayah. Jenis tanah tertentu yang tersusun dari berbagai jenis mineral mempunyai pengaruh berbeda terhadap adanya peristiwa gerakan tanah.

Ketidak homogenan tanah/batuan bawah permukaan dan karakter lingkungan lahan dipengaruhi oleh beberapa faktor antara lain unsur geologi, kondisi keairan, komposisi mineral penyusunnya dan proses sedimentasi, terutama pada material berbutir halus seperti lempung. Keberadaan lempung yang mempunyai sifat ekspansif umumnya dapat diamati dilapangan dari sifat fisik batuan yang khas berupa rekahan-rekahan pada saat kering (mengkerut) dan sifat licin dan plastis pada saat basah (mengembang) (Yulianti et al. 2012).

Sifat ekspansif pada lempung, selain disebabkan oleh ukuran butir penyusunnya juga sangat dipengaruhi oleh mineralogi penyusun lempung tersebut. Kelimpahan mineral lempung sendiri sangat bervariasi dipengaruhi oleh berbagai macam hal diantaranya adalah jenis batuan asal, pelapukan serta proses diagenesis sehingga menyebabkan terdapatnya variasi baik secara vertikal maupun lateral (Priyono, 2012).

Schäbitz et al. (2018) menjelaskan bahwa, daya kembang tanah (ekspansif) lempung antara lain tergantung pada:

1. Jenis dan jumlah mineral

2. Kemudahan bertukarnya ion-ionnya atau disebut kapasitas pertukaran kation

Untuk mengetahui faktor jenis tanah yang berpengaruh terhadap adanya kejadian gerakan tanah maka diperlukan kajian lebih mendalam tentang mineralogi jenis lempung dan sifat-sifatnya yang dampaknya berpengaruh terjadap kejadian gerakan tanah di Indonesia.

\subsection{Tujuan}

Tujuan dari kajian ini adalah menganalisis jenis-jenis mineralogi lempung dan sifat-sifatnya serta implikasinya dengan gerakan tanah di berbagai wilayah Indonesia. Diharapkan dengan kajian ini mampu memberikan kontribusi kaitannya dengan upaya mitigasi bencana gerakan tanah dan perencanaan pembangunan untuk mengurangi risiko adanya gerakan tanah di Indonesia.

\section{METODOLOGI PENELITIAN}

Kajian tentang mineralogi jenis lempung dan implikasinya dengan gerakan tanah dilakukan dengan beberapa langkah dan metode sebagai berikut:

1. Melakukan studi pustaka dan literatur baik data, informasi, maupun penelitian sebelumnya melalui penelusuran literatur berupa jurnal, buku atau website. 
2. Mendeskripsikan mineralogi lempung dan proses terbentuknya

3. Mendeskripsikan struktur tipe mineralogi lempung dan sifatsifatnya.

4. Melakukan deskripsi data yang telah didapat dan menguraikan implikasi jenis mineralogi lempung terhadap kejadian gerakan tanah.

\section{HASIL DAN PEMBAHASAN}

\subsection{Mineralogi Lempung dan Proses Terbentuknya}

Mineral lempung (clay mineral) merupakan kelompok mineral penyusun pada batuan sedimen, dengan jumlah hampir $40 \%$, juga sebagai unsur utama tanah (soil). Istilah clay digunakan di Amerika Serikat dan International Society of Soil Science, untuk menyatakan suatu batuan atau partikel mineral yang terdapat pada tanah berukuran butir kurang dari $0.002 \mathrm{~mm}$, sedangkan menurut Pettijohn (1987), lempung merupakan besar butir dalam skala Wentworth berukuran $1 / 256$ atau 0.0039 mm (Heine et al. 2010 dalam Husain, R. 2015)

Menurut Heine et al. 2010 dalam Husain, R. 2015., mineral lempung merupakan komponen yang paling umum dari semua sedimen, dan mineral lempung dapat ditemukan sebagai penyusun tanah dari kutub hingga ke daerah khatulistiwa. Mineral lempung yang dihasilkan oleh transformasi batuan induk dengan pemilahan fisik dan kimia tanpa modifikasi unsur dari mineralnya, dan oleh pelapukan kimia menyebabkan transformasi mineral primer dengan pembentukan mineral lempung sekunder. Mineral lempung sekunder membentuk suatu kompleks pelapukan yang mengakibatkan pembentukan tanah.

Pengembangan tanah dan mineral lempung dipengaruhi oleh iklim, vegetasi, fauna dan aktivitas manusia, litografi, bentang alam, air interflow, waktu. Oleh karena itu, mineral lempung dapat digunakan sebagai petunjuk menentukan batuan induknya dan kondisi iklim selama pembentukannya.

Pembentukan mineral lempung dapat terjadi melalui dua proses yaitu (1) alterasi fisik dan kimia dari mineral primer (2) pelapukan dari mineral yang segera diikuti penghabluran kembali bahan yang telah lapuk menjadi mineral lempung. Mineral illit mewakili hidrous mika terbentuk dari muskovit bila keadaannya memungkinkan lewat proses alterasi. Alterasi muskovit menjadi illit disebabkan sejumlah $\mathrm{K}^{+}$hilang dari struktur kristal dan molekul air menggantikannya, hingga menyebabkan kisi-kisinya kurang mantap pada saat proses hancuran berlangsung. Hilangnya $\mathrm{K}^{+}$yang terus menerus dan penggantian $\mathrm{Al}^{3+}$ oleh $\mathrm{Mg}^{2+}$ yang berlangsung dalam lapisan $\mathrm{Al}^{3+}$ akan berakhir dengan terbentuknya montmorillonit. Dalam beberapa hal illit dapat terbentuk dari mineral primer seperti K-feldspar, yang melalui proses penghabluran kembali dimana $\mathrm{K}^{+}$ dijumpai dalam bentuk banyak. Klorit terbentuk melalui proses alterasi biotit atau mika yang kaya $\mathrm{Fe}$ dan $\mathrm{Mg}$. Perubahan itu dibarengi dengan hilangnya sejumlah $\mathrm{Mg}^{2+}, \mathrm{K}^{+}$, dan $\mathrm{Fe}^{2+}$ (Hardjowigeno, 1987).

Alterasi dan pelapukan lebih lanjut menghasilkan illit dan vermikulit, dan salah satu dapat teralterasi lebih lanjut menjadi montmorillonit. Klorit juga dapat terbentuk dari alterasi mineral primer yang kaya $\mathrm{Fe}$ dan $\mathrm{Mg}$ seperti piroksin dan hornblende. Selain itu montmorilonit dapat juga terbentuk melalui penghabluran kembali sejumlah mineral apabila lingkungan memungkinkan. Ternyata keadaan hancuran sedang (sedikit masam hingga alkalin), adanya sejumlah $\mathrm{Mg}$ dan tidak adanya pencucian merupakan syarat bagi pembentukan montmorilonit. Kaolinit mencerminkan tingkat hancuran yang lebih lanjut dan dibentuk dari pelapukan silikat dalam reaksi sedang hingga sangat masam di mana logam alkali dan alkali tanah dibebaskan (Hardjowigeno, 1987).

Aluminium dan silikat yang larut akan menghablur kembali membentuk kaolinit. Pada saat terjadinya hancuran mineral primer dan sekunder, maka terjadi pembebasan berbagai unsur kimia. Kation-kation seperti $\mathrm{Na}^{+}$dan $\mathrm{K}^{+}$ yang mudah larut akan tercuci, sedangkan yang lain seperti $\mathrm{Al}^{3+}, \mathrm{Fe}^{2+}$ dan $\mathrm{Si}^{4+}$ dapat menghablur kembali dan menjadi mineral baru atau membentuk mineral yang tidak mudah larut seperti hidrous oksida aluminium dan besi.

Mineral lempung umumnya illit dan vermikulit, kecuali di daerah tua atau di 
daerah bercurah hujan tinggi, kaolinit akan lebih dominan (Rayes, 2006). Beberapa batuan yang cukup banyak mengandung mineral kelam (mafic) dan kandungan kuarsa rendah, disamping banyak mineral kelam (ferromagnesium), juga banyak dijumpai Ca-plagioklas. Mineral kelam dan Ca-plagioklas tersebut mudah sekali lapuk, sehingga menghasilkan tanah dengan kejenuhan basa yang tinggi dengan warna merah tua atau coklat tua karena kandungan besi bebas yang tinggi.

Selanjutnya dikatakan bahwa kaolinit dan haloisit merupakan mineral lempung yang ditemukan apabila drainase tanah baik. $\mathrm{Di}$ daerah berdrainase buruk atau di tempat dengan musim kering nyata dapat terbentuk montmorilonit.

Menurut Bambang et al. (2006), bahwa ditinjau dari mineralogi lempung terdiri dari berbagai macam penyusun mineral yang mempunyai ukuran sesuai dengan batasan yang ada. Mineral lempung merupakan koloid dengan ukuran sangat kecil (kurang dari 1 mikron). Masing-masing koloid terlihat seperti lempengan-lempengan kecil yang terdiri dari lembaran-lembaran kristal yang memiliki struktur atom yang berulang (Gambar 1 dan Gambar 2).

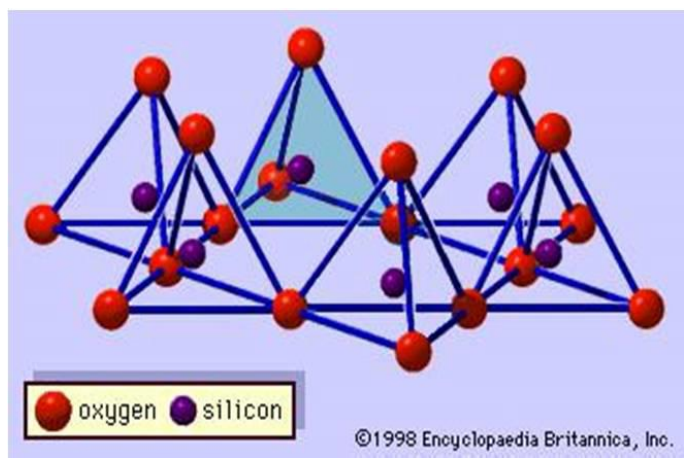

Gambar 1. Struktur Silika Tetrahedron (Encyclopedia Britannica dalam Grim, 2013).

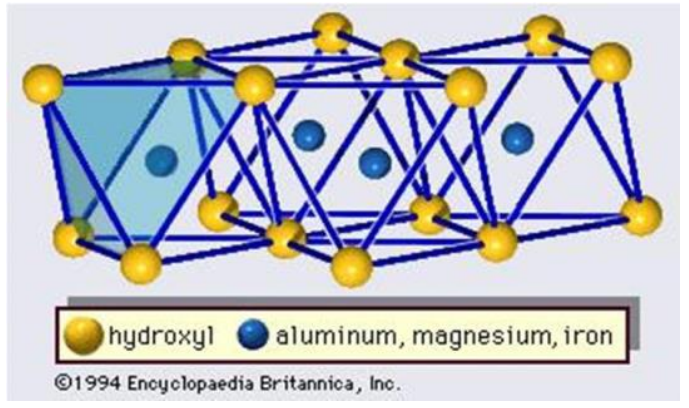

Gambar 2. Struktur Alumina Octahedron (Encyclopedia Britannica dalam Grim, 2013).

\subsection{Struktur Tipe Mineralogi Lempung dan Sifat-Sifatnya}

Terdapat 3 tipe utama mineral lempung diantaranya (kaolinite group, smectite group (montmorilonit), Illite group, yaitu:

\subsubsection{Kaolinite}

Merupakan mineral silikat berlapis (Gambar 2), struktur mineral satu banding satu (1:1) merupakan lembaran alumina oktahedran (gibbsite) membentuk satu unit dengan tebal 7.15A $(1 \AA=10-10 \mathrm{~nm})$, berwujud seperti lempengan tipis. Mineral kaolinit berwujud seperti lempengan-lempengan tipis, masing-masing dengan diameter $1000 \AA$ sampai $20000 \AA$ dan ketebalan dari $100 \AA$ sampai $1000 \AA$ dengan luasan spesifik perunit massa $\pm 15 \mathrm{~m} 2 / \mathrm{gr}$. Kaolinite memiliki kapasitas shrinkmengembang rendah, sehingga tidak dapat mengabsorpsi air dan kapasitas tukar kation rendah (1-15 meq/100g). Biasanya disebut oleh masyarakat tanah lempung putih atau tanah liat putih merupakan endapan residual.

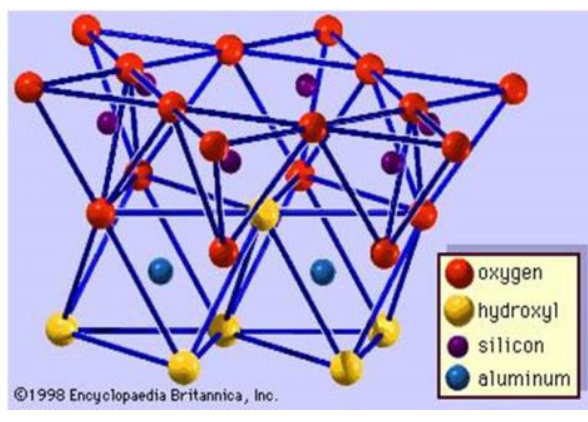

Gambar 3. Struktur 1:1 Kaolinite (Encyclopedia Britannica dalam Grim, 2013). 


\subsubsection{Montmorillonite}

Termasuk kelompok mineral smektit, struktur mineral 2:1 (Gambar 5). Tebal satu satuan unit adalah $10 \AA-18 \AA$, mempunyai beberapa sifat yang spesifik sehingga keberadaannya dapat mempengaruhi sifat fisik dan sifat kimia tanah. Struktur kisinya tersusun atas satu lempeng $\mathrm{Al}_{2} \mathrm{O}_{3}$ diantara dua lempeng $\mathrm{SiO}_{2}$. Karena struktur inilah montmorillonit dapat mengembang menyusut menurut sumbu $\mathrm{C}$ dan mempunyai sifat penting lainnya yakni mempunyai muatan negative (negative charge), yang menyebabkan mineral ini sangat reaktif terhadap lingkungan.

Mempunyai kapasitas tukar kation yang tinggi, dan kemampuannya yang dapat mengembang bila basah ataupun menyusut bila kering. Pembentukan mineral smektit memerlukan kondisi sebagai berikut:

(1) curah hujan harus cukup untuk menyebabkan terjadinya pelapukan, tapi tidak menyebabkan pencucian basa-basa dan silica;

(2) adanya masa-masa kering yang diperlukan untuk kristalisasi smektit;

(3) drainage yang terhambat sehingga terhindar dari proses pencucian dan hilangnya bahan-bahan hasil pelapukan; serta

(4) suhu tinggi untuk menunjang proses pelapukan (Driessen and Dudal, 1989 dalam Bambang et al, 2006).

\subsubsection{Illite}

Terdiri atas satu lapisan alumina antara dua lapisan silika, tebal satu satuan unit adalah $10 \AA$, tidak berubah jika diberi larutan glycol, struktur satuan kristalnya 2:1 (Gambar 4), hampir sama dengan montmorillonit.

\subsubsection{Halloysite}

Termasuk dalam kelompok kaolinit, struktur mineral satu banding satu (1:1), terdiri dari 1 lembar oktahedral dan 1 lapisan tetrahedral serta satuan unitnya $10 \AA$.

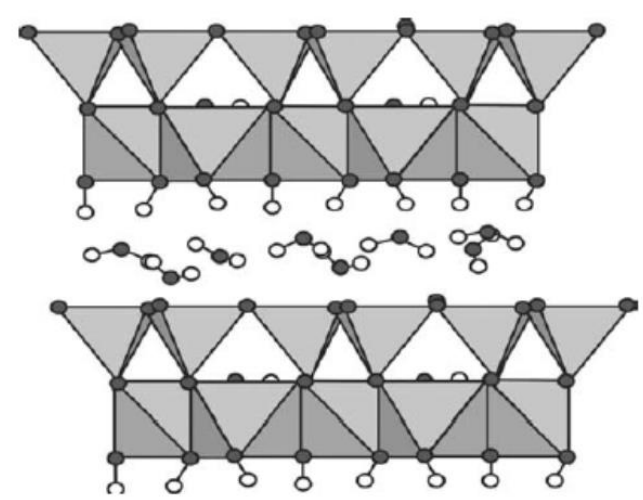

Gambar 4. Struktur Kristal Haloisit (Joussein et.al, 2005 dalam Husain, 2015.)

Disamping tiga jenis mineral lempung tersebut mineral-mineral lempung lainnya (Hermawan et al, 2003) yang sering dijumpai adalah vermiculite, chlorite (Gambar 5). 

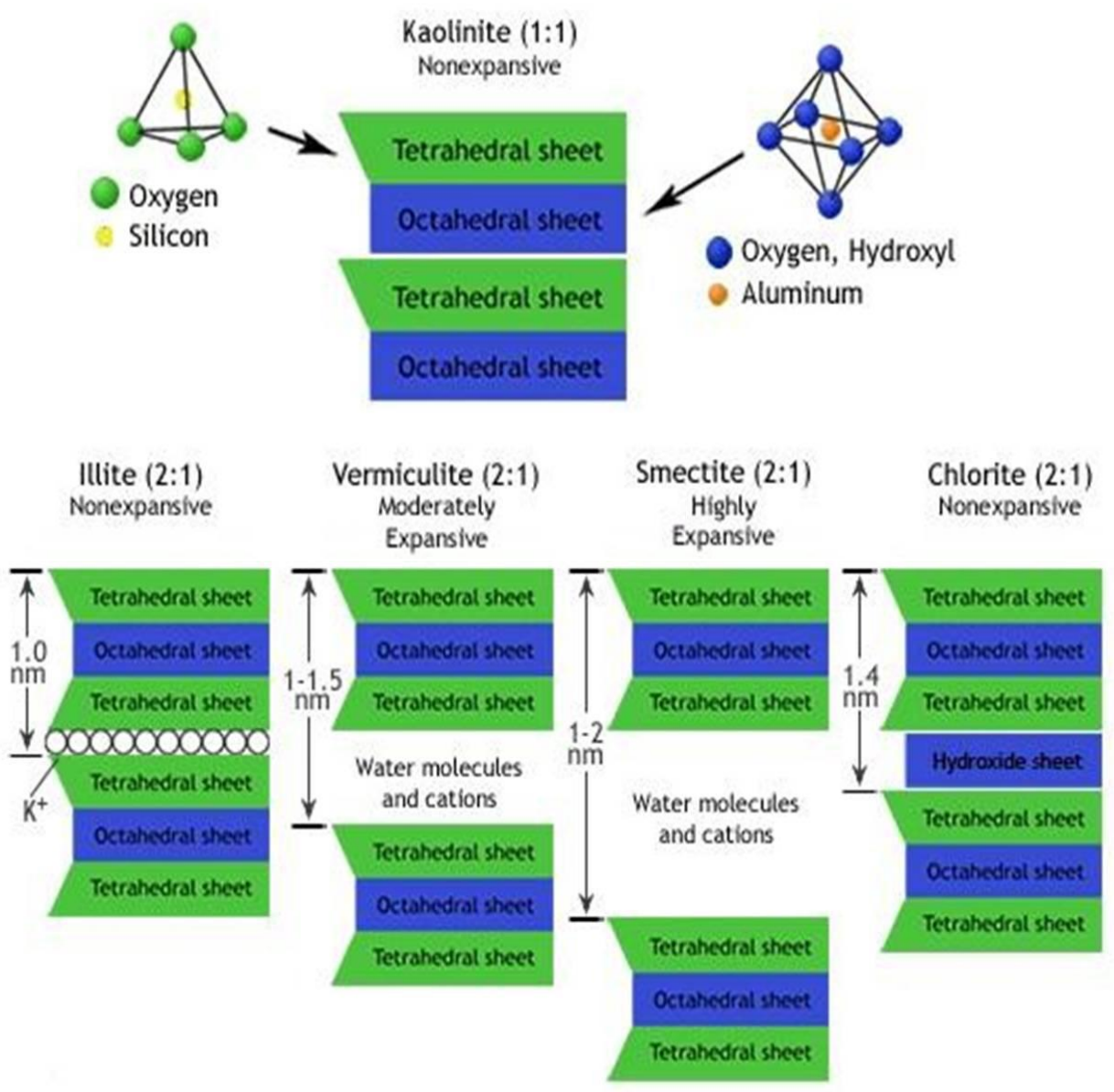

Gambar 5. Struktur Satuan Kristal Mineral Lempung (Oliver, 2013. dalam Husain, 2015.)

Sebagian besar lempung terdiri dari partikel mikroskopis dan submikroskopis (tidak dapat dilihat dengan jelas bila hanya dengan mikroskop biasa), berbentuk lempengan pipih dan merupakan partikel-partikel dari mika group, serpentinite group, mineralmineral lempung (clay mineral) dan mineral yang sangat halus lainnya.

\subsection{Implikasi Jenis Mineralogi Lempung Terhadap Kejadian Gerakan Tanah}

Beberapa penelitian yang telah dilakukan tentang pengaruh mineral lempung terhadap terjadinya gerakan tanah atau longsor diantaranya :

1. Ali Yalcin (2007), tentang pengaruh mineral lempung sebagai hasil pelapukan formasi dasitik, bahwa keberadaan mineral Illit dan montmorillonit yang memiliki sifat kembang susut pada soil tersebut.
Hal ini mengakibatkan parameter kuat geser akan sangat rendah ketika terjadi kejenuhan oleh air, sehingga menyebabkan terjadinya gerakan tanah di Wilayah Giresun Turki.

2. Amin Widodo (2011) meneliti tentang hasil pelapukan, sifat geoteknik tanah dan kondisi geokimia tanah di lereng yang berdekatan dengan bidang longsor yang telah terjadi. Tebalnya tanah residual 16 meter yang didominasi oleh material ukuran lempung-lanau, maka tanah residu volkanik Kuarter Tua G.Argopuro merupakan lereng yang kritis.

3. Kuswaji Dwi Priyono (2012) mengkaji tipe lempung terhadap intensitas dan mekanisme terjadinya longsor lahan. Perbedaan tipe, jenis, jumlah dan sebaran mineral lempung yang terbentuk terkait dengan keadaan lereng yang mempengaruhi proses transformasi ataupun pembentukan mineral lempung, pada daerah yang 
tersusun oleh batu lempung, napal pasiran, batugamping dan batuan andesit, breksi andesit dan tuff yang merupakan hasil aktivitas Gunungapi.

4. Ratna Husain (2015) mengkaji secara geokimia tipe dan jenis mineral lempung yang terkandung pada tanah residual dari batuan dasar (breksi volkanik, batugamping dan batupasir silisiklastik). Serta menentukan keterdapatan jenis mineral lempung pada setiap lapisan atau strata tanah residual pada masing-masing batuan dasar berbeda untuk menentukan hubungan mineral lempung yang mempengaruhi gerakan tanah.

Dari beberapa penelitian tersebut diatas disebutkan bahwa mineral lempung yang terbentuk dipengaruhi oleh mekanisme proses transformasi ataupun pembentukan mineral lempung yang sejalan dengan tingkat perkembangan tanah. Grim (1968) mengemukakan bahwa mineral lempung yang terbentuk dalam tanah sangat tergantung pada:

1. Kandungan $\mathrm{Si}$,

2. Macam dan konsentrasi kation yang ada,

3. $\mathrm{pH}$ tanah serta

4. Intensitas pelindian.

Interaksi antara berbagai faktor pembentuk tanah juga sangat mempengaruhi komposisi mineral lempung yang terdapat dalam suatu kondisi bentuk lahan. Jadi proses terbentuk dan komposisi jenis mineral lempung sangat spesifik di setiap bentuk lahan. Dari spesifik bentuk lahan ini berpengaruh terhadap proses yang terjadi setiap mineral lempung penyusun tanahnya.

Wilayah Indonesia yang cenderung beriklim basah sangat melimpah akan ketersediaan air dalam suatu bentuk lahan. Air sangat mempengaruhi sifat mineral lempung, karena butiran dari mineral lempung sangat halus, sehingga luas permukaan spesifikasinya menjadi lebih besar. Dalam suatu partikel lempung yang ideal, muatan negatif dalam keadaan seimbang, selanjutnya terjadi substitusi isomorf dan kontinuitas perpecahan susunannya, sehingga terjadi muatan negatif pada permukaan partikel kristal lempung. Salah satu untuk mengimbangi muatan negatif, partikel tanah lempung menarik muatan positif (kation) dari garam yang ada dalam air porinya. Hal ini disebut pertukaran ionion.

Pertemuan antara molekul air dan partikel lempung akan menimbulkan lekatan yang sangat kuat, sebab air akan tertarik secara elektrik dan air akan berada disekitar partikel lempung yang disebut air lapisan ganda, sedangkan air yang berada pada lapisan dalam disebut air resapan. Lapisan air inilah yang menimbulkan gaya tarik menarik antar partikel lempung yang disebut unhindered moisture film.

Interaksi antara molekul-molekul air dengan partikel lempung dapat melalui tiga proses:

1. Pertama, kutub positif dipolar air akan saling tarik menarik dengan muatan negatif permukaan partikel lempung.

2. Kedua, molekul air diikat oleh partikel lempung melalui ikatan hydrogen (hydrogen air ditarik oksigen atau hidroksil lain yang ada pada permukaan partikel lempung).

Proses ketiga, penarikan molekul air oleh muatan negative permukaan lempung secara berantai melalui kation yang menampung dalam larutan air. Faktor paling dominan adalah proses ikatan hydrogen.

Menurut Mitchell, 1976. dalam Widiatmono dan Siswanto, 2007. molekul air dekat permukaan akan memiliki sifat kelistrikan dan termodinamika yang berbeda dengan molekul air bebas yang sangat jauh dari daerah ikatan. Jumlah molekul air yang berinteraksi dengan permukaan lempung akan sangat dipengaruhi oleh jenis mineral yang ada yaitu pada nilai luasan permukaan spesifiknya (specific surface), seperti yang terlihat pada Gambar 6. Luas permukaan lempung merupakan faktor utama yang mempengaruhi besarnya molekul air yang ditarik untuk membentuk lapisan listrik rangkap (Diffuse Double Layer). Fenomena ini mengidentifikasikan kemanapuan mineral lempung menarik molekul air atau menunjukkan kapasitas perilaku plastis tanah lempung.

Lempung akan bersifat labil bila kationkation yang berada diantara partikel lempung adalah kation-kation yang lemah atau dapat dengan mudah digantikan oleh kation-kation yang lain atau tergeser oleh molekul-molekul air yang konsentrasinya tinggi. 
Kation yang lemah adalah kation-kation yang berasal dari garam-garam mineral yang terdapat di alam misalnya $\mathrm{Na}^{+}$. Sehingga akan dihasilkan gaya elektrostatis yang lemah serta jari-jari antar partikel besar, sehingga akan didapatkan lempung yang mengembang disaat banyak air dan menyusut pada saat air keluar dari lempung dengan perbedaan kembang susut yang besar.

Selain berinteraksi dengan molekul air, permukaan mineral lempung tanah biasanya mengandung muatan elektronegatif yang memungkinkan terjadinya reaksi pertukaran kation, muatan ini merupakan hasil dari satu atau beberapa lebih dari reaksi yang berbeda. Dua sumber utama bagi asal usul muatan negatif menurut Kim. $\mathrm{H}$. Tan (1991) yaitu:

1. Adanya subtitusi Isomorfik

Proses ini merupakan sumber utama muatan negative dalam lempung tipe 2:1. Sebagian dari silicon dalam lapisan tetrahedral dapat diganti oleh ion yang berukuran sama, yang biasanya $\mathrm{Al}^{3+}$ demikian pula sebagian dari alumunium dari lembar octahedral dapat digantikan oleh $\mathrm{Mg}^{2+}$ tanpa mengganggu struktur kristal.

2. Disosiasi gugus hidrosil yang terbuka

Keberadaan gugus -OH pada tepi kristal dapat juga mengakibatkan muatan negative khususnya pada $\mathrm{pH}$ tinggi. Hidrogen dari hidroksil (OH-) terurai sedikit dari permukaan lempung menjadi bermuatan negatif dari ion oksigen. Muatan negative tipe ini disebut muatan.

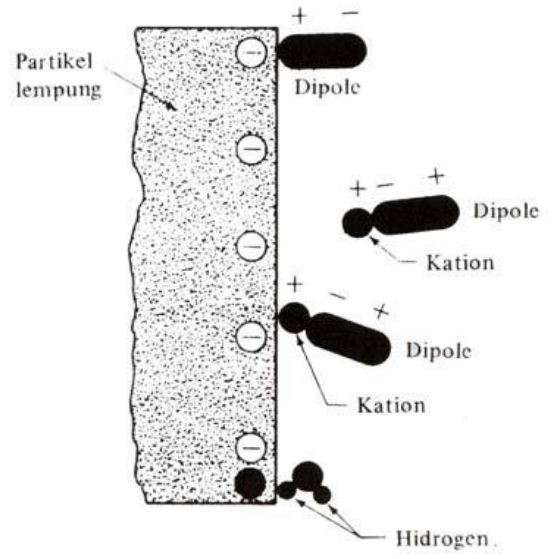

Gambar 6. Interaksi Molekul dan Air dengan Partikel Lempung (Das Braja. M, 1985 dalam Widiatmono dan Siswanto, 2007) berubah-ubah atau muatan tergantung $\mathrm{pH}$. Sebaliknya proton $(\mathrm{H}+)$ tidak hanya dapat terdisosiasi dari gugus $-\mathrm{OH}$ (hidroksil) yang terbuka tetapi dapat juga menyerap atau memperoleh proton, proses ini akan tejadi pada media yang sangat asam ( $\mathrm{pH}$ rendah) sehingga dapat menghasilkan muatan positif pada permukaan lempung.

Pada mineral lempung kering, muatan negatif pada permukaan akan dinetralkan oleh kation-kation lain yang mengelilingi partikel tersebut secara exchangeable cation (Kim H. Tan 1951). Muatan negatif pada permukaan partikel lempung beserta kumpulan ion-ion lawan yang bemuatan positif disebut lapisan rangkap listrik atau diffuse double layer. Lapisan pertama dari lapisan rangkap tersebut terbentuk dari muatan dari permukaan lempung (berupa muatan titik yang terlokasi) tetapi dianggap terbagi secara merata pada permukaan lempung. Lapisan kedua berada dalam lapisan cairan yang berdekatan dengan permukaan lempung.

\section{KESIMPULAN}

1. Mekanisme terjadinya tanah longsor di suatu lereng perbukitan/pegunungan dipengaruhi oleh komposisi tipe lempung yang terbentuk.

2. Perbedaan tipe, jenis, jumlah, dan sebaran mineral lempung yang terbentuk pada berbagai kejadian longsorlahan terkait dengan keadaan lereng yang mempengaruhi proses transformasi ataupun pembentukan mineral lempung yang sejalan dengan tingkat perkembangan tanahnya.

3. Permukaan mineral lempung tanah biasanya mengandung muatan elektronegatif yang memungkinkan terjadinya reaksi pertukaran kation.

4. Reakai pertukaran kation inilah yang menjadi indikasi mineral lempung berpotensi bersifat ekspansif sehingga terjadilah gerakan tanah.

5. Selanjutnya karakter tipe lempung digunakan sebagai dasar penyusunan upaya mitigasi bencana tanah longsor mendatang. 


\section{DAFTAR PUSTAKA}

Bambang D., Agusman, A. Maas, S.A. Siradz. 2006. Karakterisasi TanahTanah berwarna Hitam hingga Merah di atas Formasi Karst Kabupaten Gunung Kidul. Jurnal IImu Tanah dan Lingkungan Vol. 6 No.1 2006: 39-46. Fakultas Pertanian Universitas Gadjah Mada Yogyakarta.

Benjamin S. Ponto, John C.Berg. 2018. Clay particle charging in apolar media. Appllied Clay Science Vol. 161, 1 September 2018: 76-81. https://doi.org/10.1016/j.clay.2018. 04.016

Grim, R. E. (1968). Clay Mineralogy, 2nd Edition. New York: Mc.Graw-Hill

Grim, R.E., 2003. Clay Mineralogy, New York: Mcgraw Hill Book Company.

Hardjowigeno, S. 1987. IImu Tanah. Mediyatama Sarana Perkasa, Jakarta.

Husain, R. 2015. Geokimia Mineral Lempung dan Implikasinta terhadap Gerakan Tanah. Program Pasca Sarjana Universitas Hasanuddin. Makassar.

Kim. H. Tan, (1951), Dasar-Dasar Kimia Tanah. Balai Penelitian Perkebunan, Bogor. Gajah Mada University Press. Bulaksumur. Yogyakarta.
M.Schäbitz, C.Janssen, H.-R.Wenk, R.Wirth, B.Schuck, H.-U.Wetzel X.Meng, G.Dresen. 2018. Microstructures in landslides in northwest China - Implications for creeping displacements. Journal of Structural Geology. Volume 106, January 2018, Pages 70-85.

Priyono, K.D. 2012. Kajian Mineral Lempung Pada Kejadian Bencana Longsorlahan $\mathrm{Di}$ Pegunungan Kulonprogo Daerah Istimewa Yogyakarta. Forum Geografi, Vol. 26, No. 1, 54 Juli 2012: $53-64$.

Rayes, M.L. 2006. Metode Inventarisasi Sumber Daya Lahan. Andi Publisher. Yogyakarta.

Widiatmono, K. dan H. Siswanto. 2007. Stabilisasi Tanah Lempung Dengan Kapur Pertanian $\left(\mathrm{CaCO}_{3}\right)$ Di Daerah Rawa Pening Kabupaten Semarang. Jurusan Teknik Sipil Universitas Diponegoro. Semarang.

Yulianti, A., D. Sarah dan E. Soebowo. 2012. Pengaruh Lempung Ekspansif Terhadap Potensi Amblesan Tanah Di Daerah Semarang. Jurnal Riset Geologi dan Pertambangan Vol. 22 No. 2 (2012): 93-104. 